\title{
ИММУНОКОРРЕКЦИЯ В КОМПЛЕКСНОМ ЛЕЧЕНИИ ГНОЙНО-НЕКРОТИЧЕСКИХ ОСЛОЖНЕНИЙ САХАРНОГО ДИАБЕТА
}

IMMUNOCORRECTION IN THE COMPLEX TREATMENT OF PURULENT-NECROTIC COMPLICATIONS OF DIABETES MELLITUS

Z. Lovpache

A. Teuvov

Summary. The urgency of treating the main consequences of diabetes mellitus lies not only in maximizing the improvement of the quality of life, but also in preserving the affected organs and limbs. In this regard, the authors propose not only the diagnosis of earlier diagnoses and the proportion of loss of working capacity, but also the correction of immunity. As a basis for the correction of immunity, the use of immunosuppressants and the introduction of additional doses of drugs that promote wound healing and epithelization after surgery are recommended. The authors show that the ointments and gels used can act not only as secondary forms of treatment, but also as primary means of immunocorrection. According to the test results, the processes of increasing healing by $10-15 \%$ were recorded when compared with analogues, where immunosuppressants did not act as the main method of treatment.

Keywords: diabetes mellitus, immunocorrection, treatment, purulent wounds, complex application.

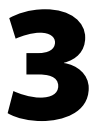
а последние годы значительно выросло количество больных сахарным диабетом типа (инсулинозависимый) и в большей степени типа II (инсулинонезависимый). Сахарный диабет и его осложнения по своему медико-социальному значению занимают третье место в мире после сердечно-сосудистых и онкологических заболеваний. Рост заболеваемости связан с увеличением численности и возраста населения, урбанизации, распространения ожирения и малоподвижным образом жизни.

Количество зарегистрированных больных сахарным диабетом в Российской Федерации составляет более 3 млн. человек. Истинное число больных в 4-5 раз больше, чем число официально зарегистрированных. Кроме того, уровень заболеваемости сахарным диабетом ежегодно увеличивается на 5-6\%. Около 25-30\% больным на сахарный диабет впервые данное заболевание диа-

\author{
Ловпаче Зарема Нурийдиновна \\ К.м.н., дочент, Кабардино-Балкарский \\ государственный университет им. Х. М. Бербекова \\ tanka70@yandex.ru \\ теувов Аслан Алексеевич \\ Кабардино-Балкарский государственный \\ университет им. Х.М. Бербекова
}

teuw@mail.ru

Аннотация. Актуальность лечения основных последствий сахарного диабета заключается не только в максимальном содействии повышения качества жизни, но также и сохранении пораженных органов и конечностей. Авторы предлагают в этой связи не только диагностику ранее поставленных диагнозов и доли потери работоспособностей, но также и коррекции иммунитета. В качестве основы для коррекции иммунитета рекомендуется использование иммуносупрессоров и введение дополнительных доз препаратов, способствующих заживлению и эпителизации раны после хирургического вмешательства. Авторы показывают, что используемые мази и гели могут выступать не только как вторичные формы лечения, но также и как первичные средства иммунокоррекции. По результатам испытаний фиксировались процессы повышения заживляемости на 10-15\% при сравнении с аналогами, где иммуносупрессоры не выступали в качестве основного метода лечения.

Ключевые слова: сахарный диабет, иммунокоррекция, лечение, гнойные раны, комплексное применение.

гностируют в хирургическом стационаре, куда они обращаются по поводу гнойно-некротических процессов различной локализации [3, с. 95].

Патогенез является мультифакторным и в развитии гнойно-некротической стадии важное значение имеет сочетание факторов, среди которых преобладают: некорректированная в течение длительного времени гипергликемия, вторичная глюкозотоксичность, поражение артерий нижних конечностей, изменения реологии и гемодинамики в микроциркулярном русле нижних конечностей, развитие периферической сенсомоторной полинейропатии, инфекция, энергетический дефицит вследствие нарушения всех видов обмена [6, с. 8].

Относительно патогенеза сахарного диабета 2-го типа, то продолжается изучение механизмов инсулинорезистентности, активности системного воспаления, 
роли адипоцитокинов (лептина, адипонектина) в развитии сахарного диабета и его сосудистых осложнений [1, c. 372].

В патогенезе развития сахарного диабета лежат полинейропатия, остеоартропатия, нарушение микроциркуляции и магистрального кровотока, на фоне которых развиваются гнойно-некротические процессы, включая анаэробные флегмоны и гангрены [4, с. 48].

Высокий уровень холестерина в плазме крови, особенно в циркулирующих атерогенных липопротеидах низкой плотности является одним из факторов риска возникновения и прогрессирования атеросклероза [2, C. 15].

Теперь повышение уровня гомоцистеина в плазме крови рассматривают как существенный фактор риска атеросклеротического поражения сосудов. Считают, что гомоцистеин подлежит автоокислению с образованием свободных радикалов, которые повреждают эндотелии сосудов с последующим развитием эндотелиальной дисфункции, что запускает сложный каскад ферментативных реакций, приводящих к индукции синтеза холестерина и окислению липопротеидов низкой плотности, что стимулирует процессы атерогенеза [9, с. 75]. Повышение концентрации С-реактивного белка также подавляет продукцию эндотелиального NO, индуцирует экспрессию молекул адгезии, усиливает поглощение липопротеидами низкой плотности макрофагами [7, с. 25]. На основе результатов проведенных исследований предполагают, что усиление процессов атерогенеза в наибольшей степени выражено у больных сахарным диабетом, а при длительном течении атеросклероза важное значение имеет вялотекущее воспаление сосудистой стенки, провоцируемое другими факторами, в частности гипергомоцистеинемией [8, с. 222].

Однако, распространенность ангиопатий при сахарном диабете объясняется еще и более важными факторами развития сосудистых осложнений: гипергликемия, глюкозирования белков, окислительный стресс, гиперинсулинемия и инсулинорезистентность. Особое значение в механизмах развития ангиопатий принадлежит остаточным средствам.

При нормальных условиях в организме сохраняется равновесие между скоростью перекисного окисления липидов и активностью антиоксидантной системы, что является основой гомеостаза. Чрезмерное увеличение продуктов перекисного окисления липидов (свободных радикалов) имеет цитотоксическое действие, приводит к разрушению клеток, что можно предупредить компенсацией углеводного обмена или путем добавления к терапии сахарного диабета антиоксидантов.
Исследования выполнили на 90 пациентах с площадью гнойной раны 10-20 см2. Для экспериментов использовали модель контактного термического ожога. Фиксировали обычно ожоговую рану IIIB степени, что подтверждено патологоанатомическими исследованиями кожи и подлежащих костных мышц. Накожно фиксировали участок, содержащий 0,1 мл суточной агаровой культуры клинического полирезистентного штамма Р aeruginosa 3101, в дозе 1,5*108 КОЕ/мл.

На вторые сутки обычно фиксировали 0,1 мл микробной суспензии, аналогичной дозе синегнойной палочки. Далее начинали лечение пораженного участка ежедневным нанесением опытного аппликационного сорбента на рану и препаратов контрольного типа в течение 21 суток.

Для оценки состояния раневой поверхности изучали сроки очищения раны от гнойно-некротических масс, время появления грануляций и начала краевой эпителизации, а также сроки полной эпителизации поверхности раны. Планиметрию раневой поверхности проводили с учетом общей площади дефекта в см2, относительной площади некроза, грануляций и эпителизации в процентах, которые исследовали на 1, 3, 7, 14 и 21 сутки лечения. Оценивали скорость заживления раневого дефекта с использованием таких показателей, как средняя скорость уменьшения раневой поверхности в см2 за сутки и уменьшение площади раны в процентах за сутки.

Все опыты воспроизводились трижды. По результатам эксперимента полное очищение ран от гнойно-некротических масс в группах, получавших оригинальный аппликационный сорбент и мазь «Argedin Bosnalek», произошло достоверно раньше на 0,9 и 0,5 суток соответственно по сравнению с группой, которая получала препарат-основу «Agen Zentiva» $(p<0,05)$. Грануляционная ткань сформировалась вероятно ранее на 1,1 суток при применении оригинального сорбента и на 0,8 суток - при использовании «Argedin Bosnalek» по сравнению с больными, получавшими препарат-основу $(p<0,05)$. Краевая эпителизация ожоговой раны в условиях применения оригинального сорбента и мази «Argedin Bosnalek» появилась достоверно раньше, чем в группе, получавшей препарат-основу «Agen Zentiva» на 1,3 и 0,8 суток соответственно ( $p<0,05)$. Полная эпителизация раневая поверхность произошла у больных, которые получали оригинальный аппликационный сорбент, произошла на 3,5 суток быстрее, чем в группе с препаратом-основой $(p<0,05)$ и на 1,7 суток раньше, чем у группы, получавших «Argedin Bosnalek» $(p<0,05)$. Индекс уменьшения раневой площади в\% за день и средняя скорость уменьшения площади раневой поверхности (мм/сутки) оказались достоверно выше в экспериментальных группах, где лечили аппликационным 
Таблица 1. Планиметрические показатели динамики заживления ран различных экспериментальных групп

\begin{tabular}{|c|c|c|c|c|}
\hline Показатели & Эксперимен & гальные группы & & \\
\hline $\begin{array}{l}\text { Полное очищение ран от гнойно- } \\
\text { некротических масс, сутки }\end{array}$ & Без лечения & $\begin{array}{l}\text { Лечение } \\
\text { сорбентом «Agen } \\
\text { Zentiva» 4,16 } 16 \\
0,26\end{array}$ & $\begin{array}{l}\text { Лечение оригинальным } \\
\text { аппликационным } \\
\text { сорбентом 3,26士0,16 }\end{array}$ & $\begin{array}{l}\text { Лечение мазью } \\
\text { «Argedin Bosnalek» } \\
3,7 \pm 0,16\end{array}$ \\
\hline Формирование грануляционной ткани, сутки & - & $4,76 \pm 0,26$ & $3,66 \pm 0,16$ & $4,0 \pm 0,24$ \\
\hline Краевая эпителизация ожоговой раны, сутки & - & $6,76 \pm 0,26$ & $5,46 \pm 0,16$ & $6,0 \pm 0,26$ \\
\hline $\begin{array}{l}\text { Полная эпителизация раневой поверхности, } \\
\text { сутки }\end{array}$ & - & $19,9 \pm 0,26$ & $16,76 \pm 0,26$ & $18,5 \pm 0,36$ \\
\hline Уменьшение площади раны,\% & - & $4,81 \pm 0,1$ & $7,06 \pm 0,03$ & $6,9 \pm 0,66$ \\
\hline $\begin{array}{l}\text { Средняя скорость уменьшения площади } \\
\text { поверхности раны (мм / сутки) }\end{array}$ & - & $0,71 \pm 0,01$ & $0,81 \pm 0,01$ & $0,82 \pm 0,01$ \\
\hline
\end{tabular}

Таблица 2. Динамика бактериального загрязнения ран, P. aeruginosa, KOE/мл $(p<0,05)$

\begin{tabular}{|c|c|c|c|c|c|}
\hline \multirow{2}{*}{ Название группы } & \multicolumn{5}{|c|}{ Срок наблюдения, сутки } \\
\hline & $1+$ & $3+$ & $7+$ & $14+$ & $21+$ \\
\hline Без лечения & $(2,5 \pm 0,29) \times 10^{8}$ & $(2,12 \pm 0,16) \times 10^{8}$ & $(3,3 \pm 0,36) \times 10^{8}$ & - & - \\
\hline Лечение сорбентом «Agen Zentiva» & $(2,56 \pm 0,23) \times 10^{7}$ & $(2,56 \pm 0,26) \times 10^{8}$ & $(1,76 \pm 0,17) \times 10^{4}$ & * & * \\
\hline $\begin{array}{l}\text { Лечение оригинальным } \\
\text { аппликационным сорбентом }\end{array}$ & $(2,26 \pm 0,27) \times 10^{5}$ & $(2,09 \pm 0,36) \times 10^{3}$ & $(1,34 \pm 0,16) \times 10^{2}$ & * & * \\
\hline Лечение мазью «Argedin Bosnalek» & $(2,24 \pm 0,27) \times 10^{6}$ & $(2,23 \pm 0,32) \times 10^{4}$ & $(1,43 \pm 0,1) \times 10^{3}$ & * & * \\
\hline
\end{tabular}

сорбентом и мазью, чем в группе, получавшей препарат-основу $(p<0,05)$ (табл. 1).

Одним из факторов, который замедляет процессы восстановления кожи, является бактериальное загрязнение раны. Критическое количество микробов, которая предопределяет развитие раневого процесса, составляет >105 микробных тел в 1 г раневой ткани. Именно поэтому в 1 фазе раневого процесса очень важно снизить микробную обсемененность ран ниже критического уровня, и местное лечение играет очень важную роль в этом.

Используя оригинальный аппликационный сорбент, удалось преодолеть критический уровень микробного загрязнения раны уже на третьи сутки лечения. Количество микроорганизмов, выделенных из раны этой группы составила $(2,09 \pm 0,36)$ x103 KOE/мл, что оказалось достоверно ниже по сравнению с другими группами $(p<0,05)$ (табл. 2). После 7+ дней лечения в группе, которая получала экспериментальный аппликационный сорбент, визуально гиперемия и отек тканей раны значительно уменьшились по сравнению с другими группами. В опытной группе без лечения синегнойная палочка оставалась в количестве $(3,3 \pm 0,36) \times 108$ KOE/мл, гнойные выделения из раны обильные. На 14 сутки лечения в других группах P aeruginosa не выделена. У пациентов, которых лечили аппликационным сорбентом и мазью
«Argedin Bosnalek», раны почти полностью эпителизировались, а у пациентов, которые получали препарат-основу «Agen Zentiva», наблюдали менее выраженную эпителизацию с частичным сохранением струпа. В 21+ срок (дней) лечения у пациентов всех экспериментальных групп из раны не высеивалось и наблюдалась полная эпителизация поверхности раны и частичное восстановление волосяного покрова.

Анализируя результаты эксперимента, можно говорить о том, что применение оригинального аппликационного сорбента и мази «Argedin Bosnalek», которая является «золотым стандартом» в лечении инфицированных ожоговых поражений, способствует более раннему заживлению ран по сравнению с препаратом-основой. Очищение ран, формирование грануляций и появление краевой эпителиализации достоверно не отличались в группах, получавших оригинальный препарат и мазь. Что касается развития полной эпителизации, то в группе с аппликационным сорбентом она состоялась достоверно раньше, чем у пациентов, которых лечили мазью «Argedin Bosnalek» $(p<0,05)$. По нашему мнению, это связано со свойствами компонентов, входящих в состав сорбента и способствовали развитию репаративных процессов в более ранние сроки по сравнению с другими группами.

Другие авторы также отмечают существенные антибактериальные, ранозаживляющие и сорбционные 
свойства сорбентов на основе высокодисперсного кремнезема с иммобилизованными на его поверхности антибактериальными препаратами для лечения гнойных операционных ран, абсцессов и флегмон мягких тканей в комплексе лечения гнойных осложнений сахарного диабета, трофических язв различной этиологии [5, с. 28].

Взаимодействие Agen Zentivaa с микробными клетками объясняется сродством с гликопротеидными структурами и фосфолипидам мембран, а также с расположенными на поверхности клеток рецепторами, ферментами и другими структурами белковой природы. Разницу в адсорбции микроорганизмов объясняют различиями в физико-химических свойствах поверхности бактерий: значение изоэлектрической точки, плотность поверхностного заряда, содержание белка в протеингликальном компоненте. Изучение взаимодействия наноразмерного кремнезема с раневой микрофлорой показало, что он одинаково интенсивно связывает как грамположительный стафилококк, так и грамотрицательную синегнойную палочку.
Разработанный оригинальный аппликационный сорбент, безусловно, обладает антимикробной активностью, что дает возможность достоверно раньше, чем в других группах, снизить микробную нагрузку в ране и тем самым ускорить процессы восстановления кожи и предотвратить развитие интоксикации.

Важно отметить, что согласно инструкции по применению «Argedin Bosnalek» нецелесообразно использовать для лечения глубоких гнойных и ожоговых ран с обильной экссудацией, именно поэтому предлагаемый препарат может стать альтернативным и перспективным среди препаратов для лечения инфицированных поражений кожи благодаря своим выраженным сорбционно-детоксикационным свойствам.

Следовательно, результаты позволяют утверждать о комплексном действии оригинального аппликационного сорбента, которая приводит к быстрой элиминации из раны мультирезистентного госпитального штамма синегнойной палочки и способствует ускорению процесса регенерации кожи.

\section{ЛИТЕРАТУРА}

1. Авдеева Е. Ю. Динамика микробного спектра и резистентности микрофлоры к антибиотикам при гнойных осложнениях диабетической стопы //В сборнике: Молодежь и медицинская наука в XXI веке Сборник трудов XX Всероссийской научной конференции студентов и молодых ученых с международным участием. 2019.

2. Бенсман В.М., Савченко Ю. П., Триандафилов К. Г. Функциональная классификация синдрома диабетической стопы и ее прикладное значение // Вестник современной клинической медицины. 2018. Т. 11. № 5.

3. Виноградов А.В., Чалый А. Н., Маловичко В. В., Бирюков Д. А. Конференция по современным подходам к лечению хирургической инфекции в многопрофильном стационаре // Военно-медицинский журнал. 2020. Т. 341. № 1.

4. Гвазава Т. Техника выполнения атипичных ампутаций на стопе у больных с осложнённым течением синдрома диабетической стопы // Вестник новых медицинских технологий. 2015. Т. 22. № 3.

5. Курлаев П.П., Гриценко В. А., Белозерцева Ю. П. Новый подход к выбору антибактериальной терапии гнойных осложнений синдрома диабетической стопы // Оренбургский медицинский вестник. 2019. Т. 7. № 4 (28).

6. Курлаев П.П., Гриценко В. А., Белозерцева Ю. П. Совершенствование подходов к антибактериальной терапии гнойно-некротических осложнений синдрома диабетической стопы // Бюллетень Оренбургского научного центра Ур0 РАН. 2019. № 3.

7. Михайлусов С.В., Моисеенкова Е. В. Клинические факторы риска развития инфицированного панкреонекроза // Вестник Дагестанской государственной медицинской академии. 2019. № 2 (31).

8. Нилова Л.Ю., Оришак Е. А., Гарифуллин Т. Ю., Оганесян Э. Г. Синдром диабетической стопы. Проблемы преаналитического этапа микробиологической диагностики // В сборнике: профилактическая медицина — 2017 сборник научных трудов Всероссийской научно-практической конференции с международным участием. 2017.

9. Шаповал С.Д., Савон И. Л., Якунич А. Н., Максимова 0. О. Резистентные и полирезистентные возбудители гнойно-некротических осложнений синдрома диабетической стопы // Новости хирургии. 2015. Т. 23. № 1.

( Ловпаче Зарема Нурийдиновна ( tanka70@yandex.ru ), Теувов Аслан Алексеевич ( teuw@mail.ru ).

Журнал «Современная наука: актуальные проблемы теории и практики» 